\title{
18
}

\section{ETHICS AND WHY THEY MATTER}

\author{
Knut N. Kjaer
}

Board members are responsible for setting the strategic priorities of the organisation and guiding the executives towards those goals. As such, boards are in charge of value creation and of ensuring that the business model is sustainable over time.

This means that managing risk is a key priority for the board. Equity owners (and increasingly wider stakeholders) want to be assured that profit created today is repeatable in the future within a tolerable amount of risk. Capital markets price risk in real time, so even risks years ahead may be reflected in the value of the firm today. The dominant risk when we consider performance and value over time is the lack of integrity in top management and the wider corporate culture.

The tone from the top (and the associated values, ethical behavioural standards, or Codes of Conduct), is set in the boardroom. The board is responsible for having in place a top management that is trustworthy and who act with integrity. It is responsible for the corporate culture being sound and healthy. To be on top of this, the board itself needs to have a clear common understanding on why such values are important for the 
risk-controlled future performance, what basic values need to be in place, and how the board must work to follow this up.

\section{Are we as the board in control of the main risk factors of the company?}

Running a business is mainly about managing risk, and organisations need to have in place an active system for this. The board must have ultimate ownership of this enterprise risk management (ERM) system and not just passively respond to risk management reports. Below are suggested some long-term non-financial risk factors that can be discussed in the boardroom. My reasoning is that it is the sustainability of performance over time that really requires sound ethical principles in an organisation. Over the shorter haul a corrupt management can fool the market and also the board. Good numbers don't necessary say much about the repeatability of the business model. Also, some boards run the risk of being preoccupied with short-term performance, quarterly and annual reporting, and so on. and not serving the role of managing risk and safeguarding longer-term value creation. So, from time to time we need to take a step back and ask:

\section{What risk factors stick out when we apply a medium- to long-term horizon?}

One such risk is poor management of the broad group of stakeholders. It is important to remember that value creation does not take place in a vacuum but is $100 \%$ dependent on the social and environmental context the organisation operates within.

- What is this context and how does the management of stakeholder relations impose risks (and opportunities) on the organisation?

- Who are our stakeholders in the broadest sense? On my list is customers, own employees, governments and regulators, societies at large, and also the environment.

- How do stakeholder relations affect the risks of our operations?

- What key performance indicators (KPIs) do we use to ensure that we manage relations with our customers well? Net promoter scores (NPS) and so on. 
- What KPIs do we apply to monitor the motivation of our employees? NPS, turnover, sick leave, and so on.

All these aspects are important as it is the board's role to monitor the trends and ask the right questions - why is this happening? what can we do? It is also the board's role to monitor the quality of stakeholder management and the risks related to long-term value creation. These key factors are all related to the governance of the organisation.

- Do we have the right quality of leadership, do they have the right incentives, do we as a board provide sufficient strategic leadership and inspiration as well as the ongoing checks and balances?

- Do we have sufficient trust in the top management?

- Do they operate in an environment of strong values and sound principles of being open and honest?

As board members, we are extremely dependent on the top management. If we don't have reason to trust the team in place, we have no chance of being on top of the risk management of the company and of taking the responsibility the owners have put on us. Ultimately, the board is in control of hiring and firing the top leaders, and in this context, is often seen as being too slow to react.

\section{How do we control the risk of fraud inside our firm?}

Fraud impacts not just the finances of an organisation but also its brand and reputation, and is a growing problem for organisations as the trend for digitalisation continues apace. Most fraud can be caught by internal controls or audit processes; however, people commit fraud for a range of reasons. Senior management teams therefore need to remain alert to changes in behaviour as prevention of fraud should always be the priority. Organisations should follow and report on the success of schemes that enable better understanding of stakeholders, such as: know your employees, know your customers, know your suppliers, and know your assets. Unfortunately, many corporate tragedies are self-inflicted, and had there been a positive "pre-loss" approach in place, the outcome would have potentially been very different. 


\section{How do we control the risk of government actions against our firm?}

A growing example of government action taken against businesses and industries would be in the realm of climate ethics and justice. There will be times where governments around the world will have to take firm action to make the necessary change in behaviours happen. The best way to control those risks, as a firm and/or an industry, is to embrace and implement the changes needed to reduce climate change. When firms and industries operate ethically, they reduce the risk and impact of actions from government, not just with regard to climate change.

\section{Do we as a board understand the values underpinning long-term stakeholder relations?}

I have already mentioned two such values: openness and honesty. Several more can be added: acting with integrity; having a moral compass; acting in the interest of the defined objectives and not self-interest; demonstrating loyalty, fairness, and concern for others; showing respect for others and being law abiding; and so on. All of these can be boiled down to: integrity.

- How does the board work to develop a common understanding of the right values for the business and set the right tone from the top?

- What is our key message on values that will uphold the right organisational behaviours and ethical standards?

\section{Do we understand why this is important?}

There is no doubt that enterprise behaviours and ethical standards are important for viability as well as the long-term sustainability of our organisations. Without these being in place, the board cannot act in the interest of long-term risk-controlled value creation, and as previously mentioned, we cannot be in control if the senior management can't be trusted.

- How has the organisation determined its actual ethical risks?

- What information on company ethics should the board receive?

- Is the CEO the ultimate "chief ethics officer"? 
- Boards should receive information on management's assessment of the organisation's ethical risk exposure.

\section{Questions to ask}

- Does the board have awareness of previous breakdowns in ethical behaviour?

- How do we ensure that our top management and corporate culture are ingrained with integrity?

- Does the organisation have all the legally required ethical guidelines in place? (whistle-blower policy and so on)

- Has the company identified the most relevant ethical topics for its operations, so it knows what to focus resources on? If so, how? (risk mapping, impact/materiality assessment, and so on)

- Does the organisation have an appropriate code of conduct (CoC) in place? How is this distributed and adopted by all managers?

- Does the board do an annual review of the CoC - to capture best practice and learning?

- Are the organisation's ethical guidelines publicly available?

- How do top management and the board act when there are breaches against the $\mathrm{CoC}$ ?

- Does the company have a plan for continuous improvement in the implementation of the ethical guidelines?

- Have both board members and employees received ethics training? Is this a regular event?

- Is ethics a regular agenda item in board meetings?

- Is someone in both the board (political) and management of the company (operational) appointed as responsible for developing, monitoring and controlling ethics/CoC? If yes, do they have both required competence and impact on decision-making?

- Are incentive schemes linked to ethical behaviours (generally and/or specifically)?

- What system do we have in place for pursuing identity checks?

- How does the board monitor and follow corporate values and culture?

- How is the whistle-blower policy implemented and how does it work? What has been the experience and learning so far?

- Does the organisation discuss ethics within its value chain? Is there a supply chain $\mathrm{CoC}$ in place? 